\title{
BMJ Open Evaluation of capillary pathologies by nailfold capillaroscopy in patients with psoriasis vulgaris: study protocol for a prospective, controlled exploratory study
}

\author{
Christine Fink, ${ }^{1}$ Samuel Kilian, ${ }^{2}$ Ines Bertlich, ${ }^{1}$ Elti Hoxha, ${ }^{1}$ Felicitas Bardehle, ${ }^{1}$ \\ Alexander Enk, ${ }^{1}$ Holger A Haenssle ${ }^{1}$
}

To cite: Fink C, Kilian S, Bertlich I, et al. Evaluation of capillary pathologies by nailfold capillaroscopy in patients with psoriasis vulgaris: study protocol for a prospective, controlled exploratory study. BMJ Open 2018;8:e21595. doi:10.1136/ bmjopen-2018-021595

- Prepublication history for this paper is available online. To view these files, please visit the journal online (http://dx.doi org/10.1136/bmjopen-2018021595).

Received 9 January 2018 Revised 12 July 2018 Accepted 13 July 2018

Check for updates

(C) Author(s) (or their employer(s)) 2018. Re-use permitted under CC BY-NC. No commercial re-use. See rights and permissions. Published by BMJ.

${ }^{1}$ Department of Dermatology, University of Heidelberg, Heidelberg, Germany ${ }^{2}$ Institute of Medical Biometry and Informatics, University of Heidelberg, Heidelberg, Germany

Correspondence to Holger A Haenssle; Holger.Haenssle@med.uniheidelberg.de

\section{ABSTRACT}

Introduction Psoriasis vulgaris was shown to be an independent factor increasing the risk of several comorbidities such as obesity, diabetes and dyslipidaemia with an increased risk of stroke and myocardial infarction. We hypothesise that early endothelial dysfunction, which plays a crucial role in the pathogenesis of atherosclerosis, may be detected by digital video nailfold capillaroscopy (DVNC) at the level of the dermal capillary microvasculature as a surrogate parameter. Nailfolds represent the only body site allowing for a non-invasive assessment of the capillary microvasculature at a horizontal plane. DVNC is a well-established diagnostic tool for in vivo assessment of the peripheral microcirculation by evaluating the morphology of dermal papillary capillaries. To date, reports on morphological changes of the nonlesional nailfold capillaries in patients with psoriasis vulgaris are scarce and the existing data are not conclusive.

Methods and analysis This is a prospective, single-centre, non-randomised, controlled, exploratory study assessing the capillary patterns in 100 subjects affected by psoriasis vulgaris. Non-lesional nailfold capillaries will be imaged by means of DVNC (Optilia Digital Capillaroscopy System, Optilia Instruments $A B$, Sollentuna, Sweden) in 50 patients affected by psoriasis vulgaris and 50 healthy controls. Assessments will include a qualitative, descriptive analysis of the nailfold capillaries' morphology, as well as a quantitative investigation (frequency, extent) of changes in capillary patterns. Moreover, patients' characteristics associated with the manifestation of nailfold capillaries' pathologies including well-known cardiovascular risk markers will be studied.

Ethics and dissemination Ethical approval was provided by the ethic committee of the medical faculty of the University of Heidelberg (Ethics approval number S-447/2017). The design and the final results of the study will be published and made available to the public.

Trial registration number DRKS00012856.

\section{INTRODUCTION}

Digital video nailfold capillaroscopy (DVNC) is routinely used for in vivo assessment of the peripheral microcirculation by evaluating the morphology of dermal papillary capillaries. ${ }^{1}$ Long before onset of clinical symptoms, pathological capillary patterns may be observed in a number of systemic diseases, which are
Strengths and limitations of this study

- Until today, there are only very few prospective, controlled studies investigating the frequency and extent of morphological changes of nailfold capillaries in patients with psoriasis vulgaris.

Within this study, several patient characteristics and their associated specific capillaroscopy patterns will be investigated in a prospective controlled setting on an unprecedented scale.

- Since this is an exploratory study, limitations arise from the small number of subjects in both groups. Moreover, a formal sample size calculation is not feasible due to the absence of a priori knowledge.

accompanied by vascular damage. Therefore, DVNC might be helpful to define surrogate parameters indicative of initial manifestation of cardiovascular disease. ${ }^{2}$ Additionally, capillary abnormalities were shown to potentially reflect the severity and long-term prognosis of underlying diseases. For instance, in systemic sclerosis, an association between a decreased capillary density and the development and the severity of pulmonary arterial hypertension was detected. ${ }^{3}$

Psoriasis vulgaris is a common chronic skin disease which is accompanied by a number of comorbidities that are possibly induced by a chronic, low-grade, systemic inflammation leading to vascular insufficiency and finally to clinically relevant atherosclerosis. ${ }^{2} 45$ Atherosclerosis in patients with psoriasis was shown to be caused by a transfer of inflammatory cells and cytokines from the skin to endothelial tissue and internal organs causing systemic inflammation. ${ }^{256}$ Endothelial dysfunction is often used as a surrogate marker for atherosclerosis and several studies have shown impaired endothelial function in patients with moderate to severe psoriasis or psoriatic arthritis. ${ }^{267}$ Besides broad evidence 
for an increased risk of large vessel atherosclerosis, previous studies also indicated changes of the microvasculature in the papillary dermis of psoriatic plaques and the synovia of psoriatic joints. ${ }^{89}$ However, until today, only little is known about changes in the microcirculation in non-lesional skin of patients with psoriasis. The reported data are controversial with regard to pathologies of nailfold capillaries, which most probably reflects the polyetiology and polymorphology of psoriasis. In one of the earliest studies, Redisch et al revealed tortuous capillaries with tight terminal convolutions in lesional and non-lesional skin of patients with psoriasis. ${ }^{10}$ A decreased capillary density, shorter capillaries, more nailfold haemorrhages and sluggish blood flow in patients with psoriasis arthritis were observed by Zaric et al when compared with healthy controls. ${ }^{11}$ A pattern with shorter and more tortuous capillaries was significantly correlated with periungual psoriatic plaques, nail pitting, onycholysis and the extent of the involved body surface in a study by Ohtsuka et $a l .^{12}$ A study by Ribeiro et al showed a lower capillary density, increased avascular areas and an increased number of coiled capillaries in the nailfold of patients with psoriasis. ${ }^{13}$ Finally, Bushan et al reported a significantly decreased capillary loop density and a reduction of arterial and venous capillary limb diameters but found no other of the previously described morphological abnormalities in any of the patients. ${ }^{14}$

The aim of our exploratory study is to generate hypotheses concerning the morphology, frequency and the extent of nailfold capillary changes in patients with psoriasis vulgaris and to identify patient characteristics possibly associated with specific pathological DVNC patterns. We hypothesise that early endothelial dysfunction as caused by the systemic inflammatory immune response in patients with psoriasis may be detected by DVNC at the level of the dermal capillary microvasculature. In addition, this exploratory study will provide the necessary prerequisites for a full-scale study with a formal sample size calculation since there is only little a priori knowledge.

\section{DESIGN/METHODS}

\section{Study design and objectives}

This is a prospective, single-centre, non-randomised, controlled exploratory study assessing the capillary patterns in 100 individuals by means of DVNC. The primary objective of this study is to generate hypotheses regarding the frequency, the extent and the morphology of capillary patterns in non-lesional skin of 50 patients that are either affected by psoriasis vulgaris alone (group A) or by psoriasis vulgaris in combination with accompanying psoriasis arthritis (group B) compared with 50 healthy subjects (group C) (figure 1). A secondary objective of this study is to identify patient characteristics that are statistically associated with specific DVNC patterns (eg, psoriasis severity, nail psoriasis, age, gender, duration of the disease, manifest cardiovascular diseases and circulating markers of endothelial damage and inflammation).

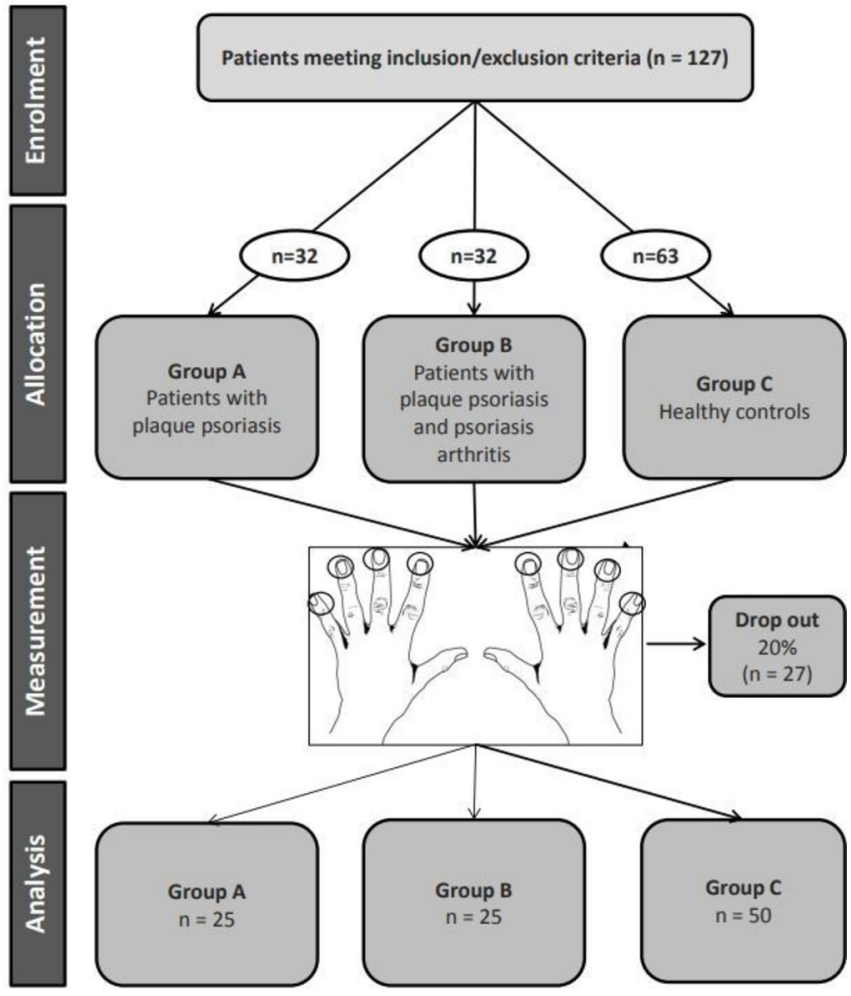

Figure 1 Flowchart of the study.

\section{Criteria for inclusion/exclusion}

Inclusion criteria for group A and B are: patients $\geq 18$ and $\leq 80$ years of age with the diagnosis of chronic moderate to severe plaque psoriasis (defined as involved Body Surface Area (BSA) $\geq 10 \%$ and/or Psoriasis Area and Severity Index (PASI) score $\geq 10$ and Dermatology Quality of Life Index (DLQI) $\geq 10$ ) with or without psoriatic arthritis for at least 6 months (duration since diagnosis may be reported by the patient). Exclusion criteria for groups A and B are: patients under current exposure to any antipsoriatic or immunosuppressive systemic therapy (discontinuation for at least 4 weeks prior to DVNC is mandatory), patients with any other skin disease or therapy affecting the area of interest for DVNC and subjects with non-plaque forms or drug-induced psoriasis as well as active ongoing inflammatory diseases other than psoriasis that might confound study evaluations. Inclusion criteria for group C (healthy subjects) are: patients $\geq 18$ and $\leq 80$ years of age with no skin disease and no inflammatory rheumatic or cardiovascular disease. Patients with any skin disease affecting the area of interest for DVNC or any active ongoing inflammatory disease that might confound study evaluations will be excluded. Patients will be excluded from all three groups if any cosmetic procedure involving the nailfold area was performed over the last 4 weeks since potential microtraumata may lead to false-positive results in DVNC. ${ }^{1516}$

\section{Methods}

In this study, the nailfold capillaries of 100 individuals will be evaluated by DVNC (Optilia Digital Capillaroscopy System, Optilia OP-120 021, Optilia Instruments 
Table 1 Parameters and morphological findings in capillaroscopy ${ }^{1519-21}$

\begin{tabular}{|c|c|c|}
\hline Parameter & Definition & Physiological image \\
\hline Capillary morphology & Vascular structure & U-shaped, parallel to nail surface \\
\hline Capillary density & Number of capillaries per linear mm & $>9-10 /$ linear mm \\
\hline Capillary enlargement & $>20 \mu \mathrm{m}$ loop diameter & Usually absent \\
\hline Megacapillaries & Homogeneously enlarged loops with a diameter $>50 \mu \mathrm{m}$ & Absent \\
\hline Tortuosity & Afferent and efferent portion cross at least two times & Usually absent \\
\hline Haemorrhages & $\begin{array}{l}\text { Extravasal detection of erythrocytes or their degradation } \\
\text { products (type A: point-like microbleeding, type B: larger } \\
\text { confluent bleeding) }\end{array}$ & Usually absent \\
\hline Elongation & Increased length of the capillaries by $50 \%$ or $350 \mu \mathrm{m}$ & Usually absent \\
\hline Pericapillary oedema & Pericapillary increase in interstitial fluid & Absent \\
\hline
\end{tabular}

AB, Sweden) (figure 1). DVNC will be performed with low magnification (x20; for global evaluation of the entire nailfold area) and high magnification (x200; for more detailed observation of separate capillaries). Nailfolds of the second to the fifth finger of both hands will be examined. For the high magnification setting, a total of 32 pictures (four consecutive images per nailfold, each covering $1 \mathrm{~mm}$ ) will be taken. ${ }^{15} 16$ For standardisation and quality assurance, the DVNC is performed after 15-20 min of acclimatisation at room temperature in a sitting position. Smoking and caffeinated beverages should be avoided at least 4 hours before DVNC to avoid capillary constriction. In our study, a semiquantitative image analysis based on the microangiopathy evolution score presented by Cutolo et al will be applied. ${ }^{15}$ The intrarater and inter-rater reliability of this semiquantitative scoring algorithm has been demonstrated. ${ }^{17}$ Interpretation of findings will be based on criteria established by the European League Against Rheumatism (EULAR) study group. ${ }^{18}$ Several capillaroscopic parameters will be evaluated and scored, for example, presence of enlarged (>20 $\mathrm{m}$ loop diameter) and giant capillaries (loop diameter $>50 \mu \mathrm{m})$, haemorrhages and/or haemosiderin deposits, capillary loss $(<9-10$ capillaries per linear $\mathrm{mm}$ counted at the distal row of the nailfold), disorganisation of the vascular array (distribution and orientation) and ramified capillaries/neoangiogenesis (tortuous, branching, bushy, coiled) (table 1). Optionally, further morphological characteristics may be described. To evaluate patient characteristics possibly associated with specific DVNC patterns, the following parameters will prospectively be assessed: the PASI score, presence of nail psoriasis such as pitting, onycholysis, hyperkeratosis, discolouration, disfiguring or haemorrhages, presence of psoriasis arthritis, demographic and clinical data (eg, age, gender, duration of the disease, drug intake, circulating markers of endothelial damage and inflammation (table 2), accompanying medical conditions (including history of cardiovascular disease)).

\section{Statistical considerations}

This is the first exploratory study investigating capillary pathologies by DVNC in patients with psoriasis vulgaris since there is only little a priori knowledge about the frequency and extent of morphological changes of nailfold capillaries in patients with psoriasis vulgaris. Thus, a formal sample size calculation is not possible. This exploratory study will provide the necessary prerequisites for a formal sample size calculation for a full-scale study.

A total of 100 complete and evaluable data sets will allow obtaining a first impression of the potential impact of psoriasis on capillary pathologies by descriptive statistics. It is planned to investigate 50 patients with psoriasis

Table 2 Circulating markers of endothelial damage and inflammation

\begin{tabular}{ll}
\hline Parameter & Standard values (SI units) \\
\hline C reactive protein (CRP) & $<0.005 \mathrm{~g} / \mathrm{L}$ \\
Von Willebrand factor & $50 \%-160 \%$ \\
\hline Fibrinogen & $150-350 \mathrm{mg} / \mathrm{dL}$ \\
\hline Leucocytes & $4-10 \times 10^{9} / \mathrm{L}$ \\
\hline Blood sedimentation & $0-20 \mathrm{~mm} / \mathrm{hour}$ \\
D-dimer & $\leq 300 \mu \mathrm{g} / \mathrm{L}$ \\
\hline Total cholesterol (TC) & $3.88-5.15 \mathrm{mmol} / \mathrm{L}$ \\
\hline Triglycerides & $<2.82 \mathrm{mmol} / \mathrm{L}$ \\
$\begin{array}{l}\text { High-density lipoprotein } \\
\text { cholesterol (HDL-C) }\end{array}$ & $\geq 1.04 \mathrm{mmol} / \mathrm{L}$ \\
Low-density lipoprotein \\
cholesterol (LDL-C)
\end{tabular}


vulgaris alone or psoriasis vulgaris accompanied by psoriasis arthritis and to compare the results to 50 healthy subjects. The resulting group allocation is sufficient to determine an effect size of 0.7 (Cohen's d) with a t test at $5 \%$ significance level and $80 \%$ power. Taking into account a dropout rate of $20 \%$, at least 127 patients shall be recruited. All endpoints will be analysed descriptively by tabulation of the measures of the empirical distributions. Depending on the scale level of the variables, means, SD, medians and first and third quartiles, as well as either minimum and maximum or absolute and relative frequency, will be reported. Descriptive $\mathrm{p}$ values of the corresponding statistical tests comparing results of patients with healthy subjects will be given, together with the associated 95\% CIs. When appropriate, graphical methods will be used to visualise the findings.

\section{Ethical considerations, dissemination plan and regulatory obligations}

The study is conducted in accordance with the Declaration of Helsinki principles (2013), applicable local government regulations and independent Ethics Committee policies and procedures. Before initiation of the study, the protocol was presented and approved. The design and the final results of the study will be presented at meetings and congresses, and will be published in written form in international scientific journals.

\section{Recruitment and status of the study}

Ethical approval was granted in September 2017. Planned date of first enrolment is July 2018. The estimated time required for recruitment of 96 patients is 12 months. The total duration of the study is expected to be 24 months, including statistical analysis.

\section{Patient and public involvement}

Patients or public were not involved in the design or conduct of the study. Study results will be made available to the public via press releases as launched by the media departments of the authors' institutions.

Contributors CF, SK, IB, EH, AE and HAH participated in the development and the implementation of the study (writing of the protocol, submission to ethics committee, data management). CF, SK, IB, EH, FB, AE and HAH helped to draft and to review the paper. All authors read and approved the final manuscript.

Funding This work was supported by a grant from Novartis Pharma GmbH, Nürnberg, Germany.

Competing interests None declared.

Patient consent Not required.

Ethics approval Independent ethicscommittee of the medical faculty of the University of Heidelberg (Ethics approval numberS-447/2017).

Provenance and peer review Not commissioned; externally peer reviewed.
Open access This is an open access article distributed in accordance with the Creative Commons Attribution Non Commercial (CC BY-NC 4.0) license, which permits others to distribute, remix, adapt, build upon this work non-commercially, and license their derivative works on different terms, provided the original work is properly cited, appropriate credit is given, any changes made indicated, and the use is non-commercial. See: http://creativecommons.org/licenses/by-nc/4.0/.

\section{REFERENCES}

1. Smith V, Thevissen K, Trombetta AC, et al. Nailfold capillaroscopy and clinical applications in systemic sclerosis. Microcirculation 2016;23:364-72.

2. Martínez-Sales V, Vila V, Ricart JM, et al. Increased circulating endothelial cells and microparticles in patients with psoriasis. Clin Hemorheol Microcirc 2015;60:283-90.

3. Hofstee HM, Vonk Noordegraaf A, Voskuyl AE, et al. Nailfold capillary density is associated with the presence and severity of pulmonary arterial hypertension in systemic sclerosis. Ann Rheum Dis 2009;68:191-5.

4. Nast A, Boehncke WH, Mrowietz U, et al. S3 - Guidelines on the treatment of psoriasis vulgaris (English version). Update. J Dtsch Dermatol Ges 2012;10(Suppl 2):S1-s95.

5. Gyldenløve M, Jensen P, Løvendorf MB, et al. 'Short-term treatment with methotrexate does not affect microvascular endothelial function in patients with psoriasis'. J Eur Acad Dermatol Venereol 2015;29:591-4.

6. Gonzalez-Juanatey C, Llorca J, Amigo-Diaz E, et al. High prevalence of subclinical atherosclerosis in psoriatic arthritis patients without clinically evident cardiovascular disease or classic atherosclerosis risk factors. Arthritis Rheum 2007;57:1074-80.

7. Pirro M, Stingeni L, Vaudo G, et al. Systemic inflammation and imbalance between endothelial injury and repair in patients with psoriasis are associated with preclinical atherosclerosis. Eur J Prev Cardiol 2015;22:1027-35.

8. Barton SP, Abdullah MS, Marks R. Quantification of microvascular changes in the skin in patients with psoriasis. Br J Dermatol 1992;126:569.74.

9. Espinoza LR, Vasey FB, Espinoza CG, et al. Vascular changes in psoriatic synovium. A light and electron microscopic study. Arthritis Rheum 1982;25:677.84.

10. Redisch W, Messina EJ, Hughes G, et al. Capillaroscopic observations in rheumatic diseases. Ann Rheum Dis 1970;29:244.53.

11. Zaric D, Clemmensen OJ, Worm AM, et al. Capillary microscopy of the nail fold in patients with psoriasis and psoriatic arthritis. Dermatologica 1982;164:10.14.

12. Ohtsuka T, Yamakage A, Miyachi Y. Statistical definition of nailfold capillary pattern in patients with psoriasis. Int J Dermatol 1994;33:779.82.

13. Ribeiro CF, Siqueira EB, Holler AP, et al. Periungual capillaroscopy in psoriasis. An Bras Dermatol 2012;87:550-3.

14. Bhushan M, Moore T, Herrick AL, et al. Nailfold video capillaroscopy in psoriasis. Br J Dermatol 2000;142:1171-6.

15. Cutolo M, ed. Atlas of capillaroscopy in rheumatic diseases. Milano: Elsevier Srl, 2010.

16. Sander O, Sunderkötter C, Kötter I, et al. Kapillarmikroskopie Durchführung und Nomenklatur. Z Rheumatol 2010;69:253-62.

17. Smith V, Pizzorni C, De Keyser F, et al. Reliability of the qualitative and semiquantitative nailfold videocapillaroscopy assessment in a systemic sclerosis cohort: a two-centre study. Ann Rheum Dis 2010;69:1092-6.

18. Smith V, Beeckman S, Herrick AL, et al. An EULAR study group pilot study on reliability of simple capillaroscopic definitions to describe capillary morphology in rheumatic diseases. Rheumatology 2016;55:883-90.

19. Klein-Weigel PF, Sunderkötter C, Sander O. Nailfold capillaroscopy microscopy - an interdisciplinary appraisal. Vasa 2016;45:353-64.

20. Jung P, Trautinger F. Capillaroscopy. J Dtsch Dermatol Ges 2013;11:731-6.

21. Chojnowski MM, Felis-Giemza A, Olesińska M. Capillaroscopy -a role in modern rheumatology. Reumatologia 2016;54:67-72. 